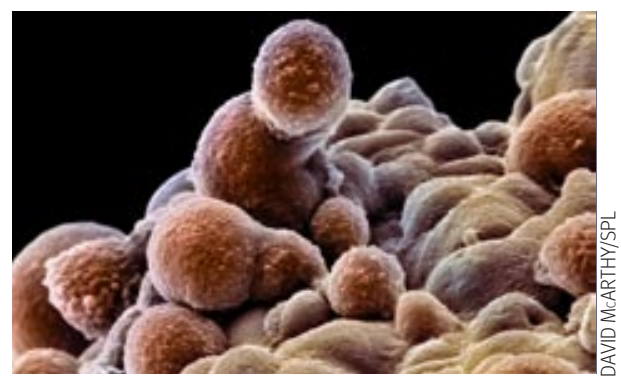

PROSTATE CANCER SCREENING

\section{Unacceptable in the under 50s}

Lane et al report the feasibility of testing for prostate cancer in men aged 45-49. ${ }^{1}$ Screening for prostate cancer in men older than 50 is hardly acceptable because overdiagnosis is obvious and the impact on mortality remains unproved despite numerous trials in the past 15 years.

Of 19 major medical organisations worldwide, only the American Cancer Society and the French and American urological associations recommend screening men for prostate cancer with annual measurement of prostate specific antigen (PSA). ${ }^{2}$ Therefore, in addition to wasting resources, the paper by Lane et al will be used to promote screening. ${ }^{1}$ In France 36\% of men underwent prostate cancer screening (unproved and not organised), whereas only 25\% underwent colorectal cancer screening (proved benefit on mortality and organised). ${ }^{3}$ The only demonstrated effect of prostate cancer screening is a $5-10 \%$ biopsy rate in the screened population, with a risk of septicaemia and haemorrhage. Plus, for those treated, various adverse effects (impotence, incontinence, pain, rectal ulcers, etc).

The recommendation from the American National Comprehensive Cancer Network for screening for PSA in men from age 40 cited by Lane et al to support their hypothesis is a view from a single department of urology. The guideline is a summary of the pros and cons and describes screening in men older than 40 in category 2B (non-uniform National Comprehensive Cancer Network consensus based on lower level evidence, including clinical experience, that the recommendation is appropriate). ${ }^{4}$

We would welcome the publication of the consent form approved by the Trent multicentre research ethics committee.

Alain Braillon doctor

braillon.alain@chu-amiens.fr

Gérard Dubois doctor, Public Health, University Hospital,

Amiens 80000, France

Competing interests: None declared.

1 Lane JA, Howson J, Donovan JL, Goepel JR, Dedman DJ, Down L, et al. Detection of prostate cancer in unselected young men: prospective cohort nested within a randomised controlled trial. BMJ 2007:335:1139-43. (1 December.)

2 Gignon M, Braillon A, Chaine FX, Dubois G. Le dépistage du cancer de la prostate: hétérogénéités des recommandations. Une exception française? Can Public Health 2007;98:212-6.

3 Dépistage du cancer: EDIFICE analyse les comportements. Écho Roche officine 2006:6. www. rochediagnostics.fr/htdocs/media/pdf/revues/ echo_roche/off20/20_p6.pdf

4 National Comprehensive Cancer Network. NCCN clinical practice guidelines in oncology. 2007. www.nccn. org/professionals/physician_gls/PDF/prostate_ detection.pdf

\section{PROGNOSTIC PESSIMISM}

\section{Don't group COPD and asthma}

We have concerns about the CAOS study's interpretation of prognostic estimates by grouping chronic obstructive pulmonary disease (COPD) and asthma together. ${ }^{1}$

Asthma and COPD are essentially different in terms of aetiology, clinical course of exacerbations, and responses to critical care interventions. Furthermore, the inhospital death rates for intubated patients are notably different, at $20-30 \%$ for COPD ${ }^{2} 3$ and about $10 \%$ for asthma. ${ }^{4}$

Both diseases have differing prognostic indicators of outcomes, which may influence intensive care clinicians' judgments on whether to admit such patients.

We believe that patients with severe asthma are much less likely to be refused admission to intensive care or intubation than patients with severe exacerbations of COPD. Furthermore, perceptions of out of hospital survival for asthma are likely to be better than for COPD. We therefore speculate that the difference between predicted and actuarial survival of the CAOS cohort is likely to have been an underestimate of the prognostic pessimism in a COPD cohort.

Is it not this particular group who we are really concerned may be "missing out" on the services of intensive care units? We would welcome the data for COPD alone. Suveer Singh consultant in intensive care and respiratory medicine, suveer.singh@imperial.ac.uk
Daffyd Lloyd anaesthesia resident

Tasneem Katawala anaesthesia resident James Harris anaesthesia resident

Radha Sabharatnam foundation year 1 , Intensive Care Unit, Magill Department of Anaesthesia, Intensive Care, and Pain Management, Chelsea and Westminster Hospital, London SW10 9HJ

Competing interests: None declared.

1 Wildman MJ, Sanderson C, Groves J, Reeves BC, Ayres J, Harrison D, et al. Implications of prognostic pessimism in patients with chronic obstructive pulmonary disease (COPD) or asthma admitted to intensive care in the UK within the COPD and asthma outcome study (CAOS): multicentre observational cohort study. BMJ 2007;335:1132-4. (1 December.)

2 Seneff MG, Wagner DP, Wagner RP, Zimmerman JE, Knaus WA. Hospital and 1-year survival of patients admitted to intensive care units with acute exacerbation of chronic obstructive pulmonary disease. JAMA 1995;274:1852-7.

3 Breen D, Churches T, Hawker F, Torzillo PJ. Acute respiratory failure secondary to chronic obstructive pulmonary disease treated in the intensive care unit: a long term follow up study. Thorax 2002;57:29-33.

4 Gupta D, Keogh B, Chung KF, Ayres JG, Harrison DA, Goldfrad C, et al. Characteristics and outcome for admissions to adult, general critical care units with acute severe asthma: a secondary analysis of the ICNARC case mix programme database. Crit Care 2004;8:R112-21.

\section{Not all bad?}

Wildman et al touch on the issue of prognosis in critically ill patients. ${ }^{1}$ They conclude that undue pessimism leads to unjustified refusal. What is shown, however, is that doctors, despite their pessimism, admit patients to the intensive care unit-a sign that they are aware of their limited prognostic capability.

Is the intensivist the right person to predict 180 day mortality? We usually don't see our patients after they have been discharged from intensive care and so have little insight into the average 180 day mortality in our patient group. In our practice, the decision to admit a patient to intensive care is made jointly with the referring specialist after discussion about the patient's short and long term prognosis. Studying this estimated prognosis would be more realistic.

The median length of stay of patients with chronic obstructive pulmonary disease (COPD) in the study is 16 days. In our intensive care unit, we have in a comparable patient group a median length of stay of 3 days with a comparable hospital survival, 6 month mortality, and 1 year mortality. ${ }^{2}$ Adjusting targets after the patient's characteristics are better known and his or her response to treatment can be evaluated will compensate for a high admission rate.

The study's conclusion is that doctors 
may be pessimistic, but they give their patients the benefit of the doubt and admit them. Prognoses should not be left to intensivists alone.

Olga M Peters-Polman intensivist

o.m.peters@anest.umcg.nl

Jan G Zijlstra intensivist

Jaap E Tulleken intensivist

John $\mathrm{H}$ Meertens intensivist

Jack J Ligtenberg intensivist Department of Critical Care,

University Medical Centre Groningen, PO Box 30.0019700

RB Groningen, Netherlands

Competing interests: None declared.

1 Wildman MJ, Sanderson C, Groves J, Reeves BC, Ayres I, Harrison D, et al. Implications of prognostic pessimism in patients with chronic obstructive pulmonary disease (COPD) or asthma admitted to intensive care in the UK within the COPD and asthma outcome study (CAOS): multicentre observational cohort study. BMJ 2007;335:1132-4. (1 December.)

2 Zijlstra GJ, Zijlstra JG, Postma DS, Wiikstra PJ, Ligtenberg JJM, Tulleken JE, et al. Acute respiratory failure in COPD: evaluation of a policy. Intensive Care Med 2006;32 (suppl 1):959.

\section{CAESAREAN SECTION}

\section{Points raised in responses}

In her rapid response, Amy B

Tuteur, an obstetrician from Sharon, Massachussetts, argues that the definition of elective is misleading in the study by Villar et al. ${ }^{2}$ "The study compares women who had vaginal deliveries with women who had medically indicated caesarean sections, both non-emergency and emergency. It never investigated elective caesareans and therefore it reaches no conclusions about them."

"Equipoise exists," writes Robert G Buist, a visiting obstetrician at the Royal Hospital for Women in Randwick, Australia. "The time has come for a large prospective long term observational study comparing outcomes for women without absolute indications for caesarean who plan to give birth by caesarean $v$ those planning to give birth vaginally."

Maureen Treadwell, a Hampshire committee member of the Birth Trauma Association, highlights that the important issue of maternal mental health is almost

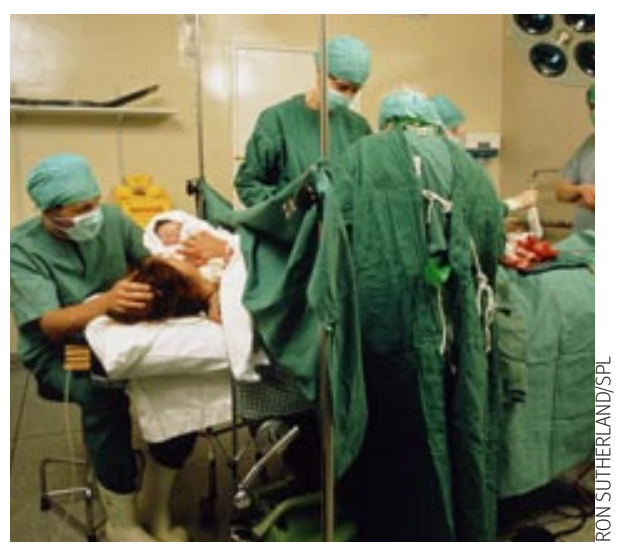

always forgotten, despite being a leading cause of death in the year around childbirth. "We represent service users and our feedback suggests that emergency caesareans and very traumatic vaginal deliveries are the most damaging in terms of mental health. These are the two types of delivery that we should really be trying to avoid. It is important that women get all the information they need to make decisions, not that which simply leads them to make decisions which suit policy makers."

Sharon Davies letters editor

sdavies@bmj.com

BMJ, BMA House, London WC1H 9JR

Competing interests: None declared.

1 Rapid responses. Maternal and neonatal individual risks and benefits associated with caesarean delivery. bmj.com 2007. www.bmj.com/cgi/eletters/335/7628/1025

2 Villar,, Carroli G, Zavaleta N, Donner A, Wojdyla D, Faundes A, et al. Maternal and neonatal individual risks and benefits associated with caesarean delivery: multicentre prospective study. BMJ 2007;335:1025-9. (17 November.)

\section{USE OF PATIENTS’ DATA}

\section{GMC guidance on confidentiality}

In the news article by Dyer, Professor Charles Warlow reports that confidentiality guidelines from the GMC (and NHS) are much more stringent than required by law. ${ }^{1}$

The article, if not Professor Warlow, implies that the Data Protection Act (DPA) is the only legal protection for patient's confidential information and that, because the act does not necessarily require consent for the use of health information in medical research, any additional requirement to seek consent is unnecessary and harmful to research.

In fact, the act requires compliance with the common law of confidentiality and other relevant statutory restrictions on the use of patients' information. The GMC's guidance on confidentiality is very much based on, and is consistent with, the common law.

The comments of Mr Philip Havers QC provide a succinct and helpful reminder of the basic common law requirements, and the GMC's guidance on confidentiality. That is that disclosure of identifiable information without consent may be justified if: it is impracticable to obtain consent; identifiable information is necessary for the purpose; disclosures are kept to the minimum necessary and it serves a demonstrably strong public interest.

John G Jenkins chair, GMC Standards and Ethics Committee General Medical Council, London NW1 3JN

pressoffice@gmc-uk.org

Competing interests: None declared.

1 Dyer C. Stringent constraints on use of patients' data are harming research. BMJ 2007;335:1114-5. (1 December.)

\section{DOCTORS AND THE STATE}

\section{How much longer will patients trust us?}

Before the British medical profession becomes too self-satisfied about the report that 5\% of East German doctors reported confidential information to the Stasi, ${ }^{1}$ we should perhaps take a look at our own practice.

Under the Multi-Agency Public Protection Arrangements (MAPPA), all NHS bodies and, indirectly, all employed doctors, are under a statutory duty to participate in local arrangements specifically designed to "promote information sharing" between all the involved agencies-a definition wide enough to encompass police and probation, social services, housing, education, jobcentres and registered landlords. The MAPPA routinely expects disclosure of substantial amounts of information obtained in the doctor-patient relationship; in some cases this provides most or all of the information available to it. People who are understandably reluctant to reveal certain information to the police or social services may report this more freely in what they believe to be a confidential clinical setting. They may still trust us now, but for how much longer?

Working under the mission statement "Protecting communities from violent and sexual offenders"-something that might look out of place above the door of a consulting room-the MAPPA has extended substantially the longstanding practice of disclosing clinical information to state agencies in areas such as driver licensing and public health, with little resistance from the medical profession and virtually no attempt to inform patients that the rules have changed. Perhaps we are reassured that information, once disclosed to the wide range of participating agencies, is still considered to be "confidential": our patients are unlikely to be so sanguine, and may have another word for it.

Only 5\% of East German doctors worked as "unofficial spies" for the state-we should be so lucky.

Christopher $\mathrm{N}$ Jones consultant forensic psychiatrist, Norvic Clinic, Norwich NR7 OHT

christopher.jones@nwmhp.nhs.uk

Competing interests: None declared.

1 Tuffs A. One in 20 East German doctors spied on patients or colleagues. BMJ 2007;335:1113. (1 December.) 